\title{
Schnyder corneal dystrophy and associated phenotypes caused by novel and recurrent mutations in the UBIAD1 gene
}

Cerys J. Evans ${ }^{1 \dagger}$, Lubica Dudakova ${ }^{2 \dagger}$, Pavlina Skalicka ${ }^{2,3}$, Gabriela Mahelkova ${ }^{4}$, Ales Horinek ${ }^{5,6}$, Alison J. Hardcastle ${ }^{1}$, Stephen J. Tuft ${ }^{7}$ and Petra Liskova ${ }^{2,3^{*}}$

\begin{abstract}
Background: The purpose of this study was to identify the genetic cause and describe the clinical phenotype of Schnyder corneal dystrophy (SCD) in six unrelated probands.

Methods: We identified two white Czech, two white British and two South Asian families with a clinical diagnosis of SCD. Ophthalmic assessment included spectral domain optical coherence tomography (SD-OCT) of one individual with advanced disease, and SD-OCT and confocal microscopy of a child with early stages of disease. UBIAD1 coding exons were amplified and Sanger sequenced in each proband. A fasting serum lipid profile was measured in three probands. Paternity testing was performed in one family.

Results: A novel heterozygous c.527G>A; p.(Gly176Glu) mutation in UBIAD1 was identified in one Czech proband. In the second Czech proband, aged 6 years when first examined, a previously described de novo heterozygous c.289G $>A$; p.(Ala97Thr) mutation was found. Two probands of South Asian descent carried a known c.305G >A; p.(Asn102Ser) mutation in the heterozygous state. Previously reported heterozygous c.361C>T; p.(Leu121Phe) and c.308C>T; p.(Thr103lle) mutations were found in two white British families. Although crystalline deposits were present in all probands the affected area was small in some individuals. Corneal arcus and stromal haze were the most prominent phenotypical feature in two probands. In the Czech probands, SD-OCT confirmed accumulation of reflective material in the anterior stroma. Crystalline deposits were visualized by confocal microscopy. Mild dyslipidemia was found in all three individuals tested.
\end{abstract}

Conclusion: Although de novo occurrence of mutations in UBIAD1 is extremely rare, SCD should be considered in the differential diagnosis of bilateral corneal haze and/or crystal deposition, especially in children.

Keywords: Schnyder corneal dystrophy, UBIAD1, Novel mutation, De novo, Crystalline deposits, Confocal microscopy, Spectral domain optical coherence tomography

\section{Background}

Schnyder corneal dystrophy (SCD; MIM \#121800) is a rare autosomal dominant disorder characterized by bilateral corneal opacification due to an accumulation of unesterified cholesterol and phospholipids in the corneal stroma [1].

\footnotetext{
* Correspondence: petra.liskova@lf1.cuni.cz

${ }^{+}$Cerys J. Evans and Lubica Dudakova contributed equally to this work. ${ }^{2}$ Research Unit for Rare Diseases, Department of Paediatrics and Adolescent Medicine, First Faculty of Medicine, Charles University and General University Hospital in Prague, Ke Karlovu 2, 12808 Prague 2, Czech Republic

${ }^{3}$ Department of Ophthalmology, First Faculty of Medicine, Charles University and General University Hospital in Prague, Prague, Czech Republic Full list of author information is available at the end of the article
}

Approximately $50 \%$ of individuals have crystalline deposits [2]. An association with genu valgum and systemic hyperlipidemia has also been reported [3].

SCD is caused by mutations in the UBIAD1 gene (MIM "611632), encoding a membrane-embedded UbiA prenyltransferase domain-containing protein which catalyses the $\mathrm{Mg}^{2+}$-dependent transfer of a hydrophobic polyprenyl chain onto a variety of acceptor molecules, including vitamin $\mathrm{K}$ and coenzyme $\mathrm{Q}[1,4,5]$. At least 26 mutations that cause SCD have been identified to date [6].

In this study we report the clinical and genetic investigation of six probands of white and South Asian origin.

(c) The Author(s). 2018 Open Access This article is distributed under the terms of the Creative Commons Attribution 4.0 International License (http://creativecommons.org/licenses/by/4.0/), which permits unrestricted use, distribution, and 


\section{Methods}

\section{Clinical examination}

The study was approved by the relevant research ethics committees and adhered to the tenets of the Helsinki Declaration. Previously unreported probands from six families with a clinical diagnosis of SCD were investigated; two were recruited in the Czech Republic and four in the UK (Table 1). Family history of SCD was documented and available family members were invited to participate.

Ophthalmic examination included best corrected Snellen visual acuity (BCVA) converted to decimal values, intraocular pressure, and fundal examination after pupil dilation. We performed corneal imaging of probands 1 and 2 using spectral domain optical coherence tomography (SD-OCT) (Spectralis; Heidelberg Engineering $\mathrm{GmbH}$ ). Proband 2 also underwent scanning slit confocal microscopy equipped with a non-applanating 40× immersion objective lens (Confoscan 3.0; Nidek Technologies, Viconza, Italy) [7].

We measured the fasting serum lipid profile of three probands and recorded the levels of total cholesterol, high and low-density lipoproteins, and triglycerides. The presence of joint deformity, scoliosis or learning difficulty was based on self-reported symptoms.

\section{Molecular genetic analysis}

Genomic DNA from probands and any additional available family members was extracted from venous blood samples using a Gentra Puregene blood kit (Qiagen, Hilden, Germany) or from saliva using an Oragene kit (Oragene OG-300, DNA Genotek, Canada). We then performed PCR amplification and Sanger sequencing of the two $U B I A D 1$ coding exons and exon/intron boundaries (primer sequences and conditions are listed in Table 2). Variants were annotated against the reference sequence for transcript NM_013319.2. Mutation description followed standard nomenclature guidelines (http://varno men.hgvs.org/) starting with nucleotide numbering c.1 at the A of the ATG translation initiation codon. Pathogenicity was evaluated in silico by six different algorithms (PROVEAN [8], SNPs\&GO [9], MutPred [10], SIFT [11], PolyPhen-2 [12] and MutationTaster [13]). We also performed paternity testing in family 2, using a previously published set of markers [14]. The population frequency of variants was determined by the Genome Aggregation Database (gnomAD), which provides sequencing data from more than 123,136 exomes and 15,496 genomes from unrelated individuals of various ethnic backgrounds [15], and 2500 Czech control chromosomes available through the next generation sequencing projects of the Czech National Center for Medical Genomics (https://ncmg.cz/en).

Table 1 Demographic and clinical data of six probands with Schnyder corneal dystrophy

\begin{tabular}{|c|c|c|c|c|c|c|c|c|c|c|c|c|}
\hline \multirow[t]{2}{*}{ No } & \multirow[t]{2}{*}{ Ethnicity } & \multirow{2}{*}{$\begin{array}{l}\text { Family } \\
\text { history }\end{array}$} & \multirow{2}{*}{$\begin{array}{l}\text { UBIAD1 } \\
\text { mutation }\end{array}$} & \multirow{2}{*}{$\begin{array}{l}\text { Age (when } \\
\text { recruited)/ } \\
\text { gender }\end{array}$} & \multicolumn{2}{|c|}{ BCVA } & \multirow[t]{2}{*}{ Corneal phenotype } & \multirow{2}{*}{$\begin{array}{l}\text { Chol } \\
(\mathrm{mmol} / \mathrm{l})\end{array}$} & \multirow{2}{*}{$\begin{array}{l}\mathrm{HDL} \\
(\mathrm{mmol} / \mathrm{l})\end{array}$} & \multirow{2}{*}{$\begin{array}{l}\mathrm{LDL} \\
(\mathrm{mmol} / \mathrm{l})\end{array}$} & \multirow{2}{*}{$\begin{array}{l}\text { TG } \\
(\mathrm{mmol} / \mathrm{l})\end{array}$} & \multirow{2}{*}{$\begin{array}{l}\text { Other relevant } \\
\text { clinical data }\end{array}$} \\
\hline & & & & & $\mathrm{LE}$ & RE & & & & & & \\
\hline 1 & $\begin{array}{l}\text { White } \\
\text { Czech }\end{array}$ & Y & $\begin{array}{l}\text { c. } 527 G>A \\
\text { p.(Gly176Glu) }\end{array}$ & $36 / \mathrm{M}$ & 0.6 & 0.7 & $\begin{array}{l}\text { Subepithelial central } \\
\text { and mid-peripheral } \\
\text { crystals in a ring } \\
\text { pattern, minimal } \\
\text { corneal arcus }\end{array}$ & 5.72 & 1.58 & 3.21 & 1.51 & \\
\hline 2 & $\begin{array}{l}\text { White } \\
\text { Czech }\end{array}$ & $N$ & $\begin{array}{l}\text { c.289G }>\text { A } \\
\text { p.(Ala97Thr) }\end{array}$ & $6 / F$ & 0.6 & 0.5 & $\begin{array}{l}\text { Subepithelial mid- } \\
\text { peripheral and } \\
\text { mid-stromal crystals } \\
\text { in a ring pattern }\end{array}$ & 4.89 & 1.31 & 2.66 & 2.05 & \\
\hline 3 & $\begin{array}{l}\text { White } \\
\text { British }\end{array}$ & $\begin{array}{l}\text { Not } \\
\text { known }\end{array}$ & $\begin{array}{l}\text { c.361C>T } \\
\text { p.(Leu121Phe) }\end{array}$ & $10 / \mathrm{M}$ & 0.3 & 0.3 & $\begin{array}{l}\text { Mid-stromal central } \\
\text { crystals }\end{array}$ & 5.00 & 1.90 & UA & 1.80 & $\begin{array}{l}\text { Amblyopia in BE } \\
\text { Lamellar } \\
\text { keratoplasty in } \\
\text { RE and LE at the } \\
\text { age of } 10 \text { and } \\
12 \text { years }\end{array}$ \\
\hline 4 & $\begin{array}{l}\text { White } \\
\text { British }\end{array}$ & Y & $\begin{array}{l}\text { c.308C>T } \\
\text { p.(Thr1031le) }\end{array}$ & $54 / F$ & 0.5 & 0.66 & $\begin{array}{l}\text { Central stromal haze, } \\
\text { arcus, few mid-peripheral } \\
\text { subepithelial crystals }\end{array}$ & $U A^{*}$ & UA & UA & UA & \\
\hline 5 & $\begin{array}{l}\text { South } \\
\text { Asian }\end{array}$ & Y & $\begin{array}{l}\text { c.305G>A } \\
\text { p.(Asn102Ser) }\end{array}$ & $37 / F$ & 0.66 & 0.66 & $\begin{array}{l}\text { Diffuse stromal haze, } \\
\text { few subepithelial } \\
\text { mid-peripheral crystals }\end{array}$ & UA & UA & UA & UA & $\begin{array}{l}\text { Knee deformities, } \\
\text { scoliosis, learning } \\
\text { difficulties }\end{array}$ \\
\hline 6 & $\begin{array}{l}\text { South } \\
\text { Asian }\end{array}$ & Y & $\begin{array}{l}\text { c.305G>A } \\
\text { p.(Asn102Ser) }\end{array}$ & $40 / F$ & 0.5 & 0.66 & $\begin{array}{l}\text { Central stromal haze, } \\
\text { arcus, few subepithelial } \\
\text { mid-peripheral crystals }\end{array}$ & UA & UA & UA & UA & \\
\hline
\end{tabular}

$B C V A$ best corrected visual acuity, $L E$ left eye, $R E$ right eye, $B E$ both eyes, $M$ male, $F$ female, $C h o l$ total cholesterol, $H D L$ high density lipoprotein, $L D L$ low density lipoprotein, TG triglycerides, *- elevated but value not known, UA unavailable data

Elevated values are shown in bold 
Table 2 Primer sequences and condition used for PCR and Sanger sequencing of UBIAD1 gene

\begin{tabular}{llllll}
\hline Target & Forward primer & Reverse Primer & Size (bp) & Enzyme & Annealing Temp \\
\hline exon 1 & CCGTCCTTCCTCCTTCCC & AAGCCACCTTTGACATCCCT & 700 & GoTaqGreen & $65{ }^{\circ} \mathrm{C}$ \\
exon 2 & CCACCTGCACAGTCTAAGGA & CTGCCAAATCACATTCCTTCCT & 689 & GoTaqGreen & $60{ }^{\circ} \mathrm{C}$
\end{tabular}

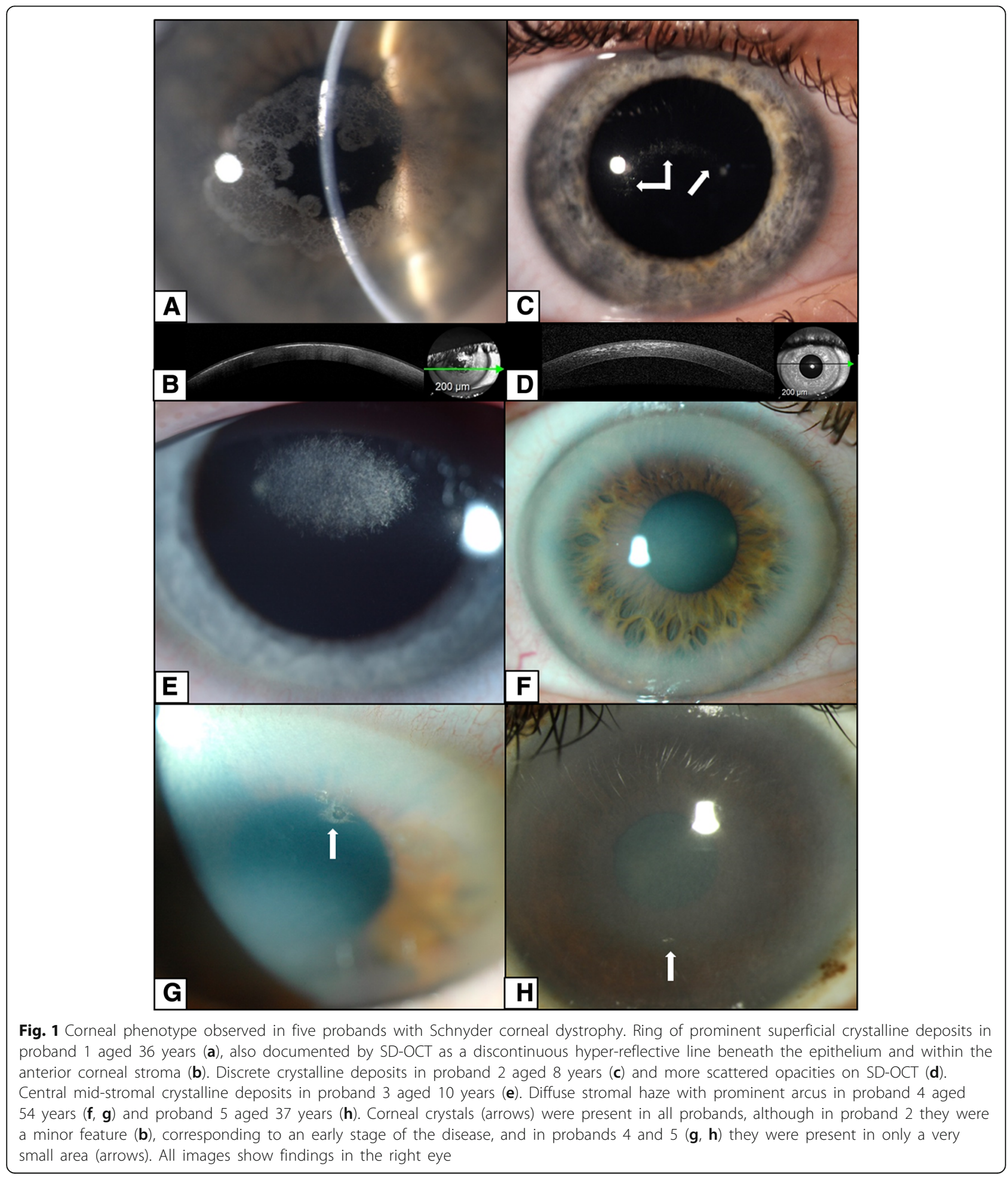




\section{Results}

Clinical, demographic and genotype data for all six probands are summarized in Table 1 . There was no family history of SCD in two pedigrees; however, in family 3 the disease status of the proband's mother was unavailable. The corneal phenotypes were diverse and included anterior and mid-stromal crystalline deposits, diffuse stromal haze and arcus lipoides (Fig. 1). There was an incremental accumulation of corneal deposits with age, and the corneal changes were symmetric in all individuals. There were corneal crystals in all probands, although these deposits were minimal in some individuals (Fig. 1 g, h). Corneal crystals were present at slit lamp examination of proband 2 at age 6 years, but neither parent had signs of corneal disease. The patient was re-examined at the age 8 years, when an increase in the corneal crystals was noted (Fig. 1b), but the visual acuity had remained unchanged (Table 1).

Corneal imaging highlighted the presence of crystals. With SD-OCT there were highly reflective deposits in the anterior stroma of probands 1 and 2 (Fig. 1c, d), with confocal microscopy there were bright reflective crystalline deposits identified in the anterior stroma of proband 2 (Fig. 2e). On confocal microscopy small round deposits were also identified in the superficial epithelial cells (Fig. 2a), in and around anterior stromal keratocytes (Fig. 2d) and in mid-stroma (Fig. 2f). The basal epithelial cells, sub-epithelial nerves, posterior stroma and corneal endothelium all appeared normal (Fig. 2b, c, g, h).

Coexisting systemic disease was present in some probands. Proband 5 and her affected sister both had bilateral knee deformities, although their affected mother was normal (Fig. 3). In proband 1 a fasting lipid profile showed high levels of total cholesterol $(5.72 \mathrm{mmol} / \mathrm{l}$; normal values in adults $<5.17 \mathrm{mmol} / \mathrm{l}$ ) [16] and in probands 2 and 3 there was a borderline elevation of total cholesterol to $4.89 \mathrm{mmol} / \mathrm{l}$ and $5.00 \mathrm{mmol} / \mathrm{l}$, respectively (normal values in children $<4.40 \mathrm{mmol} / \mathrm{l}$ ) [17].

A novel c.527G $>$ A; p.(Gly176Glu) variant, predicted to be pathogenic or probably pathogenic by all six bioinformatic tools (Table 3), was identified in proband 1 of Czech origin. The amino acid residue Gly-176 is highly conserved and located in the transmembrane domain of UBIAD1, therefore a mutation is likely to disrupt the transmembrane helices and active site [18]. Czech proband 2 harboured a known UBIAD1 c.289G>A; p.(Ala97Thr) mutation. This variant was absent in both parents, suggesting a de novo origin that was confirmed by paternity testing. The white British probands had previously reported mutations c.361C $>\mathrm{T}$; p.(Leu121Phe) [19] and c.308C >T; p.(Thr103Ile) [6]. Two reportedly unrelated British families of South Asian origin, both harboured a known c.305G $>$ A; p.(Asn102Ser) mutation [19-21]. Pedigrees and segregation of the respective

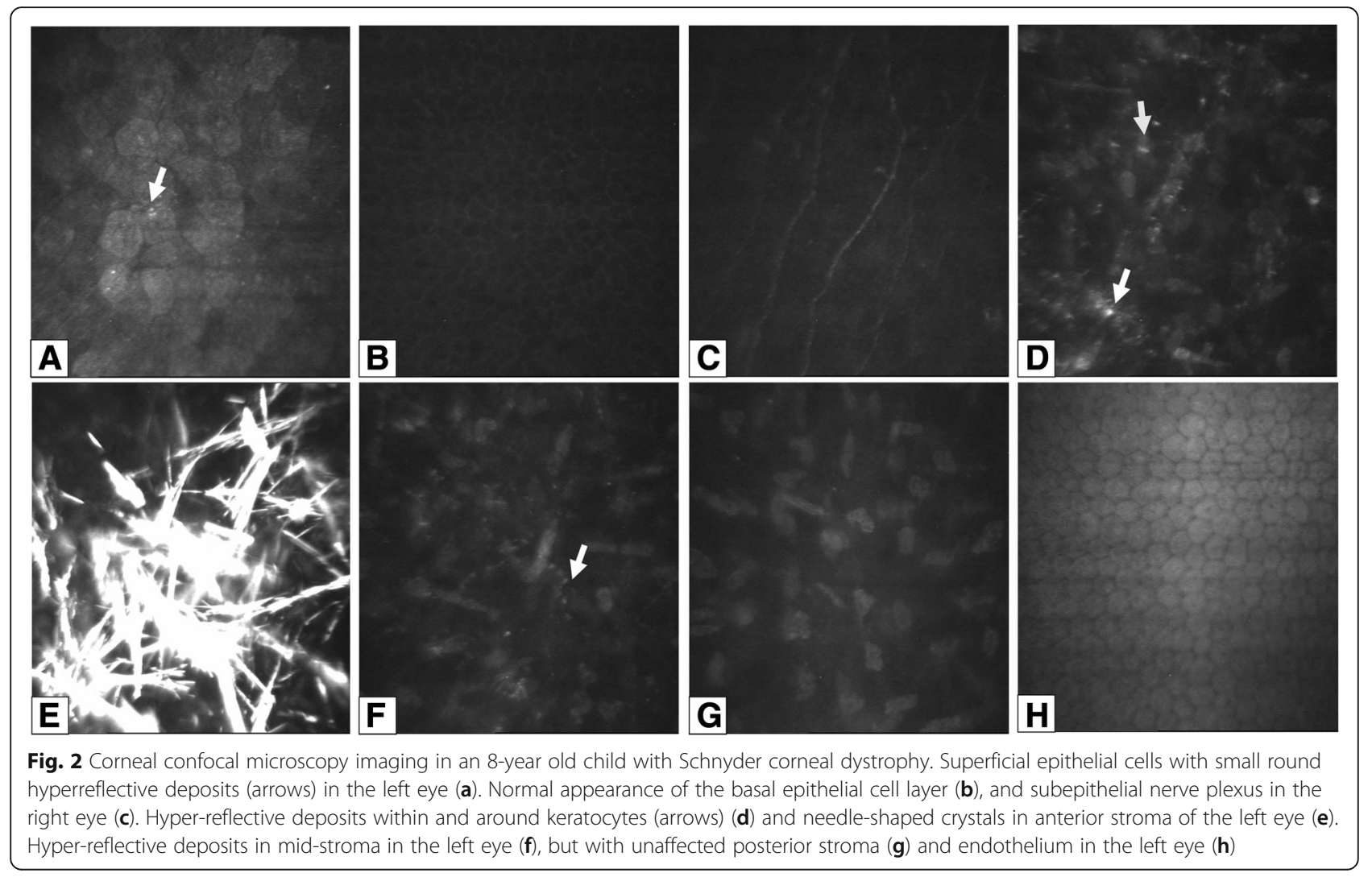




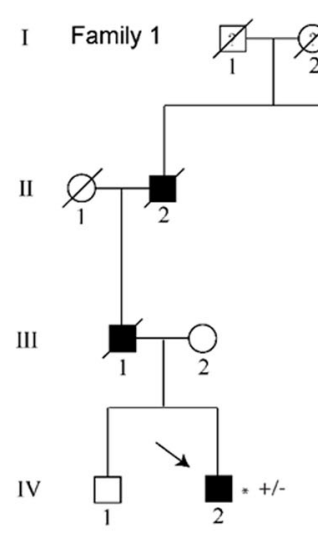

Family 3

I
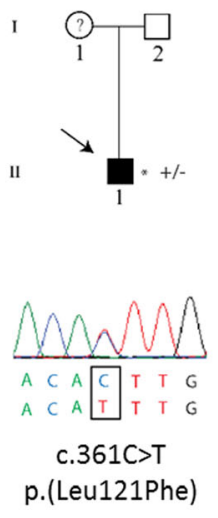

Family 5

II

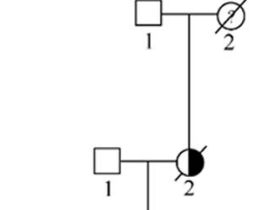

III

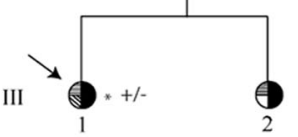

Family 4

Family 2

I $\quad-/ \cdot \mathrm{O}_{1}{ }_{2}-\square_{2} \cdot-/-$
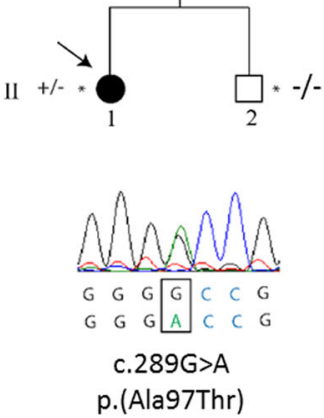

3

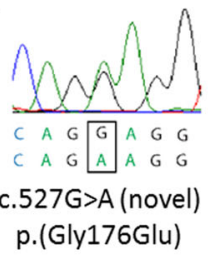

II

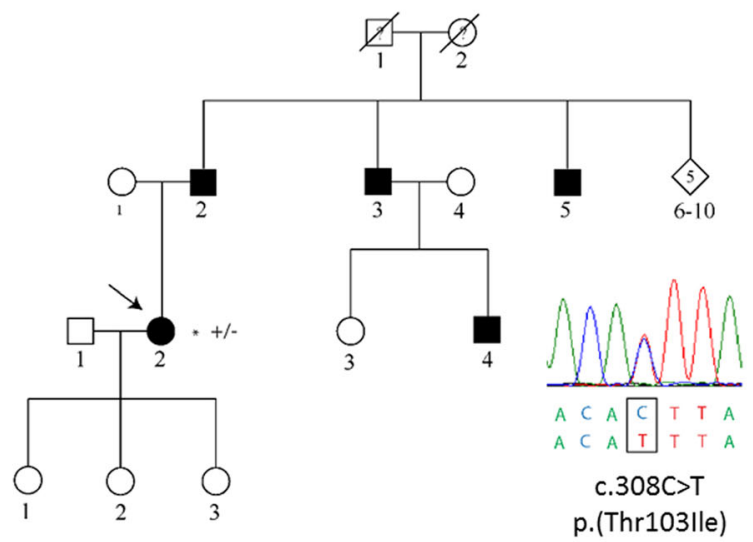

Fig. 3 Pedigrees of the six families with Schnyder corneal dystrophy. Sequence electropherograms of the identified heterozygous mutations in UBIAD1 are also shown. The mutation arose de novo in family 2. Probands are indicated by an arrow and examined individuals by an asterisk. Mutation status in tested subjects is shown $+/$ - for those who are heterozygous for a mutation in UBIAD1 and -/- for those who do not carry the pathogenic variant. Individuals known to be affected by Schnyder corneal dystrophy are shown in black, whereas a question mark indicates that the disease status of the individual was unknown

heterozygous UBIAD1 mutations are shown in Fig. 3. None of the UBIAD1 pathogenic changes found in the current study were observed in the gnomAD dataset or in the Czech control population. All of the in silico algorithms predicted that the detected mutations were pathogenic or likely pathogenic, except for SNP\&GO prediction for previously reported variant c.361C $>\mathrm{T}$; p.(Leu121Phe) [19] (Table 3).

\section{Discussion}

In this study we report the phenotype and genotype of six families with SCD. Five different UBIAD1 mutations were 
Table 3 In silico analysis of UBIAD1 missense variants identified in patients with Schnyder corneal dystrophy in the current study

\begin{tabular}{|c|c|c|c|c|c|c|}
\hline & MutPred & Polyphen2 & PROVEAN & SNP\&GO & SIFT & MutationTaster \\
\hline p.(Ala97Thr) & Disease & Probably damaging & Disease & Disease & Disease & Disease \\
\hline p.(Leu121Phe) & Disease & Probably damaging & Disease & Benign & Disease & Disease \\
\hline p.(Thr103lle) & Possibly damaging & Probably damaging & Disease & Disease & Disease & Disease \\
\hline p.(Asn102Ser) & Disease & Probably damaging & Disease & Disease & Disease & Disease \\
\hline p.(Gly176Glu) & Possibly damaging & Probably damaging & Disease & Disease & Disease & Disease \\
\hline
\end{tabular}

Six different algorithms were used; tolerated and neutral scores are indicated in green as benign; yellow indicates a possibly damaging variant, and red was used for a probably damaging and disease-causing mutation

As for MutPred an overall probability score $>0.5$ was considered as possibly damaging and a score $>0.75$ was considered as disease-causing. NM_013319.2,

NP_037451.1 and ENST00000376810.5 were used as reference sequences

identified in a heterozygous state, of which one, c.527G>A; p.(Gly176Glu), was novel. The youngest proband was found to harbour a de novo c.289G $>A$; p.(Ala97Thr) mutation, previously identified in an Irish-French family [18]. To the best of our knowledge, this is only the second observation of a spontaneously occurring mutation in an SCD patient [6]. The family history provided by proband 3 also indicated possible de novo occurrence of the identified mutation, but unfortunately this could not be confirmed as parental DNA samples were unavailable.

The c.305G>A; p.(Asn102Ser) mutation, identified in two South Asian probands, is the most frequently occurring $U B I A D 1$ mutation. It has been reported in several populations including the Czech Republic, Poland, Taiwan and China, supporting the hypothesis that it is a mutation hotspot [19-22]. One white British proband had a c.361C>T; p.(Leu121Phe) mutation, previously observed in three SCD families from the UK, America and Saudi Arabia [19, 23]. The c.308C>T; p.(Thr103Ile) mutation, detected in one white British individual, has previously been described in a proband of Japanese-European descent [6].

The clinical course of SCD is associated with characteristic corneal opacities that increase with age. Initially, central corneal haze and/or crystals are present; this was observed in our youngest proband, who was 6 years old when first examined. Arcus lipoides typically develops in the third decade, followed by mid-peripheral corneal haze in the late fourth decade [24], as documented in the current case series (probands 1, 4-5). Corneal crystals are present in approximately $50 \%$ of patients with SCD [2]. Interestingly, crystals were found in all six of our probands, although in two probands the area of crystal deposit was very small. However, the number of individuals we examined is relatively low compared with prior studies [2].

Confocal microscopy has previously been performed in two children with SCD, both at a similar age as our proband 2 [25]. Our findings corroborate observations of accumulation of crystal/reflective material in anterior stroma, both intra- and extracellularly. Interestingly, unlike the previous study, subepithelial nerves appeared normal and we were able to detect tiny reflective deposits in the corneal epithelium. Electron microscopy of corneas with SCD has also documented lipid accumulation inside epithelial cells $[26,27]$.

The differential diagnosis of crystalline corneal deposition includes monoclonal gammopathy and cystinosis. These conditions should be considered in any individual with corneal crystals who does not have a family history of SCD. Laboratory investigation should be guided by the presence of associated symptoms and patient age.

Dyslipidemia and genu valgum have been reported to be associated with SCD $[3,28]$. Three of the six probands in this study had fasting serum lipid testing. Total cholesterol was elevated in one proband and borderline levels were found in the other two probands. Self-reported knee deformities were only present in proband 5 and her sister, although their mother was not affected, which may indicate that other genetic or environmental factors influence the expression of this trait.

\section{Conclusions}

SCD should be considered in the differential diagnosis of any unexplained corneal haze and/or crystal deposition, even in the absence of a family history of corneal disease.

\section{Abbreviations}

BCVA: Best corrected visual acuity; gnomAD: Genome Aggregation Database; MIM: Mendelian Inheritance in Man; SCD: Schnyder corneal dystrophy; UBIAD1: UbiA prenyltransferase domain-containing protein

\section{Acknowledgements}

We thank The Czech National Center for Medical Genomics (https://ncmg.cz/en) (LM2015091) for providing ethnically matched population frequency data (project CZ.02.1.01/0.0/0.0/16_013/0001634).

\section{Funding}

This work was supported by UNCE 204064 and PROGRES-Q26/LF1 programs of the Charles University, Fight for Sight, Moorfields Eye Charity, Rosetrees Trust, and the National Institute for Health Research Biomedical Research Centre based at Moorfields Eye Hospital NHS Foundation Trust and UCL Institute of Ophthalmology. PS was supported by GAUK 250361/2017, SW 260367/2017 and PROGRES Q25/ LF1/2. GM was supported by MH CZ - DRO, Motol University Hospital, Praque, Czech Republic 00064203. The views expressed are those of the authors and not necessarily those of the NHS, the NIHR or the Department of Health. This work was performed within the framework of ERN-EYE.

\section{Availability of data and materials}

The datasets used and/or analysed during the current study are available from the corresponding author on reasonable request. 


\section{Authors' contributions}

CJE and LD provided molecular genetic analysis, paternity testing was done by AH. PS, GM, SJT and PL contributed in clinical data collection and analysis AJH, SJT and PL contributed to study design and writing. All authors read and approved the final manuscript.

\section{Ethics approval and consent to participate}

The study was approved by the Ethics committee of the General University Hospital in Prague (reference no. 151/11 S-IV) or Moorfields Eye Hospital (REC references 13/LO/1084 and 09/H0724/25). Written consent was obtained from all participants or their parents/legal guardians before inclusion.

\section{Consent for publication}

Not applicable.

\section{Competing interests}

The authors declare that they have no competing interests.

\section{Publisher's Note}

Springer Nature remains neutral with regard to jurisdictional claims in published maps and institutional affiliations.

\section{Author details \\ ${ }^{1}$ UCL Institute of Ophthalmology, London, UK. ${ }^{2}$ Research Unit for Rare Diseases, Department of Paediatrics and Adolescent Medicine, First Faculty of Medicine, Charles University and General University Hospital in Prague, Ke Karlovu 2, 12808 Prague 2, Czech Republic. ${ }^{3}$ Department of Ophthalmology, First Faculty of Medicine, Charles University and General University Hospital in Prague, Prague, Czech Republic. ${ }^{4}$ Department of Ophthalmology, Second Faculty of Medicine, Charles University and Motol University Hospital, Prague, Czech Republic. ${ }^{5}$ rd Department of Medicine, Department of Endocrinology and Metabolism, First Faculty of Medicine, Charles University and General University Hospital in Prague, Prague, Czech Republic. ${ }^{6}$ Institute of Biology and Human Genetics, First Faculty of Medicine, Charles University and General University Hospital in Prague, Prague, Czech Republic. ${ }^{7}$ Moorfields Eye Hospital, London, UK.}

Received: 22 January 2018 Accepted: 6 September 2018

Published online: 17 September 2018

\section{References}

1. Weiss JS, Kruth HS, Kuivaniemi H, Tromp G, White PS, Winters RS, et al. Mutations in the UBIAD1 gene on chromosome short arm 1, region 36, cause Schnyder crystalline corneal dystrophy. Invest Ophthalmol Vis Sci. 2007:48:5007-12.

2. Weiss JS, Moller HU, Aldave AJ, Seitz B, Bredrup C, Kivelä T, et al. IC3D classification of corneal dystrophies--edition 2. Cornea. 2015;34:117-59.

3. Hoang-Xuan T, Pouliquen Y, Gasteau J. Schnyder's crystalline dystrophy. II. Association with genu valgum. J Fr Ophtalmol. 1985;8:743-7.

4. Orr A, Dube MP, Marcadier J, Jiang H, Federico A, George S, et al. Mutations in the UBIADI gene, encoding a potential prenyltransferase, are causal for Schnyder crystalline corneal dystrophy. PLoS One. 2007;2:e685.

5. Li W. Bringing bioactive compounds into membranes: the UbiA superfamily of intramembrane aromatic prenyltransferases. Trends Biochem Sci. 2016;41: 356-70.

6. Lin BR, Frausto RF, Vo RC, Chiu SY, Chen JL, Aldave AJ. Identification of the first de novo UBIAD1 gene mutation associated with Schnyder corneal dystrophy. J Ophthalmol. 2016;2016:1968493.

7. Mahelkova G, Filous A, Odehnal M, Cendelin J. Corneal changes assessed using confocal microscopy in patient with unilateral buphthalmos. Invest Ophthalmol Vis Sci. 2013;54:4048-53.

8. Choi Y, Sims GE, Murphy S, Miller JR, Chan AP. Predicting the functional effect of amino acid substitutions and indels. PLoS One. 2012;7:e46688.

9. Calabrese R, Capriotti E, Fariselli P, Martelli PL, Casadio R. Functional annotations improve the predictive score of human disease-related mutations in proteins. Hum Mutat. 2009;30:1237-44.

10. Li B, Krishnan VG, Mort ME, Xin F, Kamati KK, Cooper DN, et al. Automated inference of molecular mechanisms of disease from amino acid substitutions. Bioinformatics. 2009;25:2744-50.
11. Kumar P, Henikoff $\mathrm{S}, \mathrm{Ng} \mathrm{PC}$. Predicting the effects of coding nonsynonymous variants on protein function using the SIFT algorithm. Nat Protoc. 2009:4:1073-81.

12. Adzhubei IA, Schmidt S, Peshkin L, Ramensky VE, Gerasimova A, Bork P, et al. A method and server for predicting damaging missense mutations. Nat Methods. 2010;7:248-9.

13. Schwarz JM, Rodelsperger C, Schuelke M, Seelow D. MutationTaster evaluates disease-causing potential of sequence alterations. Nat Methods. 2010;7:575-6.

14. Evans CJ, Liskova P, Dudakova L, Hrabcikova P, Horinek A, Jirsova K, et al. Identification of six novel mutation in ZEB1 and description of the associated phenotypes in patients with posterior polymorphous corneal dystrophy 3. Ann Hum Genet. 2015;79:1-9.

15. Lek M, Karczewski KJ, Minikel EV, Samocha KE, Banks E, Fennell T, et al. Analysis of protein-coding genetic variation in 60,706 humans. Nature. 2016; 536:285-91.

16. Expert panel on detection, evaluation, and treatment of high blood cholesterol in adults. Executive summary of the third report of the National Cholesterol Education Program (NCEP) expert panel on detection, evaluation, and treatment of high blood cholesterol in adults (adult treatment panel III). JAMA. 2001;285:2486-97.

17. American Academy of Pediatrics. Committee on nutrition. Cholesterol in childhood. Pediatrics. 1998;101:141-7.

18. Nickerson ML, Bosley AD, Weiss JS, Kostiha BN, Hirota Y, Brandt W, et al. The UBIAD1 prenyltransferase links menaquinone-4 [corrected] synthesis to cholesterol metabolic enzymes. Hum Mutat. 2013;34:317-29.

19. Weiss JS, Kruth HS, Kuivaniemi H, Tromp G, Karkera J, Mahurkar S, et al. Genetic analysis of 14 families with Schnyder crystalline corneal dystrophy reveals clues to UBIAD1 protein function. Am J Med Genet A. 2008;146A:271-83.

20. Du C, Li Y, Dai L, Gong L, Han C. A mutation in the UBIAD1 gene in a Han Chinese family with Schnyder corneal dystrophy. Mol Vis. 2011;17:2685-92.

21. Nickerson ML, Kostiha BN, Brandt W, Fredericks W, Xu KP, Yu FS, et al. UBIAD1 mutation alters a mitochondrial prenyltransferase to cause Schnyder corneal dystrophy. PLoS One. 2010;5:e10760.

22. Nowinska AK, Wylegala E, Teper S, Lyssek-Boron A, Aragona P, Roszkowska AM, et al. Phenotype-genotype correlation in patients with Schnyder corneal dystrophy. Cornea. 2014;33:497-503.

23. Al-Ghadeer H, Mohamed JY, Khan AO. Schnyder corneal dystrophy in a Saudi Arabian family with heterozygous UBIAD1 mutation (p.L121F). Middle East Afr J Ophthalmol. 2011;18:61-4.

24. Weiss JS, Khemichian AJ. Differential diagnosis of Schnyder corneal dystrophy. Dev Ophthalmol. 2011;48:67-96.

25. Vesaluoma MH, Linna TU, Sankila EM, Weiss JS, Tervo TM. In vivo confocal microscopy of a family with Schnyder crystalline corneal dystrophy. Ophthalmology. 1999;106:944-51.

26. Rodrigues MM, Kruth HS, Krachmer JH, Willis R. Unesterified cholesterol in Schnyder's corneal crystalline dystrophy. Am J Ophthalmol. 1987;104:157-63.

27. Rodrigues MM, Kruth HS, Krachmer JH, et al. Cholesterol localization in ultrathin frozen sections in Schnyder's corneal crystalline dystrophy. Am J Ophthalmol. 1990;110:513-7.

28. Kohnen T, Pelton RW, Jones DB. Schnyder corneal dystrophy and juvenile, systemic hypercholesteremia. Klin Monatsbl Augenheilkd. 1997;211:135-7.

\section{Ready to submit your research? Choose BMC and benefit from:}

- fast, convenient online submission

- thorough peer review by experienced researchers in your field

- rapid publication on acceptance

- support for research data, including large and complex data types

- gold Open Access which fosters wider collaboration and increased citations

- maximum visibility for your research: over $100 \mathrm{M}$ website views per year

At BMC, research is always in progress.

Learn more biomedcentral.com/submissions 